Theories \& Applications, the International Edition

Printed Version : (ISSN 2090-5262)

Online Version : (ISSN 2090-5270)

November 2014, Volume 4, No. 3 Pages (22 - 29)

\title{
Mechanics of Technical Performance for a Creative Method in High Jump.
}

\section{Dr. Omer Mohamed Labib Hassan}

Assistant professor, Department of kinetics faculty of physical education Minia University, Egypt.

\begin{abstract}
The study aimed at designing two instructional programs for performing high jump skill in athletics, the first is the creative method (chest method) and the second is fosbury flop and recognizing, after implementing both the programs, Kinematic variables ( displacement, velocity, angular change) for performing both methods, by following the experimental descriptive methods by using cinematography on a purposive sample of (10) second graders at faculty of physical education - minia university They were divided into two equivalent groups, one is the experimental method for the creative method and the other is the control for the conventional method.Observation physical tests and experts surveys are the most important methods to collect data. The results revealed the in crease of Kinematic variables values (under study) as well as record level for the experimental group learners than the control indicating the effectiveness of the creative method.
\end{abstract}

\section{Introduction:}

$\mathrm{T}$ he stunning development which international levels in the field of athletics in general, and jump higher especially have reached is due to the many sports science and foremost biomechanics that aims at developing the basic art technique sports in order to the fullest extent of effectiveness. Diversity of methods of technical performance is the best feature in the sport of athletics, which can achieve the goal of each competition according to the competition law. This will allow for specialists to develop the used methods and invent new ones. So high jump has a chance to be developed, as several techniques have appeared. Back Technique is the most commonly used which achieved the world digital achievements. As the main mechanical goal of high jump is to achieve maximum vertical distance or access the center of gravity to the highest possible point in order to pass the crossbar,that has been confirmed by "Adashevskiy,V.M" , "Lermakov.S.S" ,"Marchenko.A.A" 2013, "Bastawesi Ahmed" 1997 and "talha Hussin" 1993 that high jump is such a motor achievement aim to pass a vertical bar against the earth gravity using only one of the two feet or to launch the whole body for the maximum vertical height according to the competition roles $(1: 157),(7: 236),(21: 13)$, It is through the generation of maximum vertical launch speed of body`s center of gravity as well as the wideness of the rotation around himself and about the crossbar would enable it to achieve the best technical performance and the digital level in this competition .

Therefore the researcher has creates a new technique called "Chest Technique" as athlete`s chest face the crossbar. This technique relies on multistage rapid perpendicular approaching (running then somersault) and then compound and rapid upgrading (waving, swinging and pushing) and then multistage flying (pelvis drawing-in then knee up) and then a safe landing on the back and thighs. More of torque and speed of motor performance can be generated through this technique that lead to a highest altitude of distance of jump . Here appeared the importance of this search but actually it is an innovative technique that still unknown,so the researcher has done this study in order to make this theoretical idea becomes fact based on right scientific foundations .

\section{Aim:}

This research aim at designing two programs in order to perform high jump skill and and recognizing, after implementing both the programs :

1- The values of core mechanical variables of high jump skill in (innovative) Chest Technique for the experimental group .

2- The values of core mechanical variables of high jump skill in ( traditional ) Back Technique for the control group .

3- make a comparison of the values of core mechanical variables of high jump skill between the innovative Chest Technique for the experimental group and traditional Back technique for the control group that values of core mechanical variables include distribution timetable for the stages of performance, "horizontal, vertical and resultant displacement horizontal, vertical and resultant speed, angular change around the point of upgrading "body center of gravity " -the angular change of shoulder and thigh jointshorizontal and vertical displacement of the hands and feet during the performance stages.

\section{Method:}

It has been chosen intentionally from The student of second year at faculty of physical education-Minia University for the academic year 2012/2013, who haven`t learnt high jump skill yet at 18-20 years old. which was 20 students. They have been divided into two equal groups in order to learn high jump skill in athletics. The first group has learnt the 
skill by Chest Technique(innovative) and the second one by Bach Technique(traditional). It has been shown equivalent between two groups in some variables like: age, body and physical and mental abilities.

Table (1)

Differences significant between the two groups in age, body, physical and mental variables.

\begin{tabular}{|c|c|c|c|c|c|c|c|c|}
\hline \multirow[b]{2}{*}{ significant } & \multirow[b]{2}{*}{ (T) Value } & \multicolumn{2}{|c|}{$\begin{array}{l}\text { Back Technique } \\
(\text { traditional })\end{array}$} & \multicolumn{2}{|c|}{$\begin{array}{c}\text { Chest Technique } \\
\text { (innovative ) }\end{array}$} & \multirow[b]{2}{*}{$\begin{array}{c}\text { Measurement } \\
\text { Unit }\end{array}$} & \multirow[b]{2}{*}{ Variables } & \multirow[b]{2}{*}{ Nom } \\
\hline & & 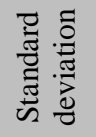 & Mean & 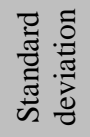 & Mean & & & \\
\hline No & 0.86 & 06.84 & 172.01 & 4.39 & 169.69 & $\mathrm{Cm}$ & Length & 1 \\
\hline No & 0.59 & 08.04 & 69.65 & 8.19 & 67.39 & $\mathrm{Kg}$ & Weight & 2 \\
\hline No & 1.19 & 00.53 & 19.83 & 0.74 & 19.47 & Year & Age & 3 \\
\hline No & 0.56 & 04.92 & 09.86 & 07.00 & 11.45 & $\mathrm{Cm}$ & Flexibility & 4 \\
\hline No & 1.32 & 01.37 & 05.33 & 01.55 & 06.24 & Second & Speed & 5 \\
\hline No & 0.34 & 02.00 & 06.22 & 01.82 & 06.53 & Second & Fitness & 6 \\
\hline No & 0.26 & 01.89 & 07.57 & 01.47 & 07.78 & Second & Accordance & 7 \\
\hline No & 0.54 & 00.18 & 00.39 & 00.13 & 00.35 & $\mathrm{Cm}$ & Power & 8 \\
\hline No & 0.74 & 07.24 & 63.15 & 06.69 & 60.72 & Degree & Intellgance & 9 \\
\hline
\end{tabular}

$\mathrm{n}=20(\mathrm{~T})$ value of the table at level $(0.05)=2.10$

Table (1) has shown calculated value (T) is less than tabled value (T), which means that there is no statistical significant differences between the two groups in the mentioned variables.This means that there is equivalent between them In there the tested has been performed in 29/2/2012 and it divided into : Physical tests : test of lurching on the box in order to measure the flexibility of back and thigh muscles) ( test of running $30 \mathrm{~m}$ to measure the speed transition) ( test of rebound running to measure agility)(test of numbered circles to measure neuromuscular compatibility) ( test of vertical leaping from stable position in order to measure the ability of legs`muscles) $(16: 346,381,406,425,395)$, and Mental tests : Cattlle test for general intelligence ( $3: 7$ ).

- implement the two suggested programs : The two programs of the research have been implanted in 5-3-2012 to 11-4-2012 through two lectures per week; every lecture takes 60 minutes. It has been taken into account to take on the lecture and the content of athletic method for second year student in the faculty.

- Post-measurement : It has been done on 16-4-2012 in the skill aspects to perform high jump skill by the technique of each group in the sample of the research at Minia StadiumMinia university at 12 p.m, that has been realized by using the following instruments and tools- The equipments : Restameter to measure the length and weight, (3 Cameras "Sony,25MB/Sec"),( Tripod with water balance),(Control and guide marks "Phosphorous adhesive strips (lengh:25cm,width:2.5cm) around body`s joints), (1metre) (3Video tapes"8mm"), (Flasher in order to synchronize between the cameras), ( computer with Motion Track program ) - Stop watch,Metre (10m).applications to submit the personal data of the sample, the data of the attempts, the data of cameras 'place, physical abilities .Poll applications to submit experts' opinion about the axes of the proposed educational programs.

\section{- The used statistical instruments:}

Arithmetic Average, Standard Deviation, (t) test 
Table (2)

The temporal distribution of stages of high jump performance skill in tow technique ( chest - back) .

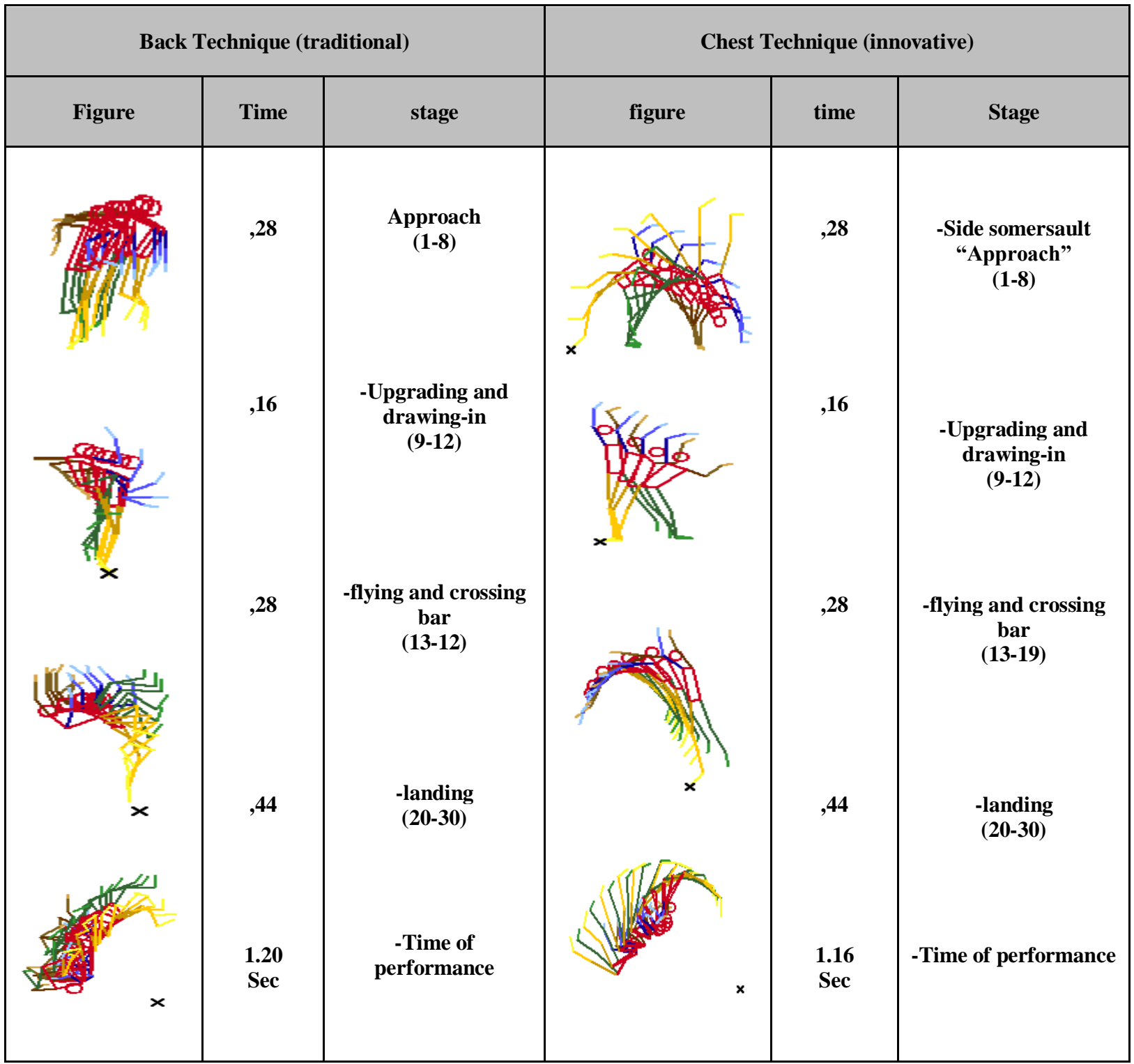


Table (3)

Biomechanics for the two technique (Chest-Back) in the high jump competition

\begin{tabular}{|c|c|c|c|c|c|c|c|c|c|}
\hline \multicolumn{2}{|c|}{ Landing } & \multicolumn{2}{|c|}{ Flying } & \multicolumn{2}{|c|}{ Upgrading } & \multicolumn{2}{|c|}{ Approach } & \multirow[t]{2}{*}{ Stage } & \multirow[b]{2}{*}{ Technique } \\
\hline End & Start & End & Start & End & Start & End & Start & & \\
\hline $1.76^{-}$ & $0.78^{-}$ & $0.70^{-}$ & 0.02 & 0.14 & 0.51 & 0.62 & 1.53 & Horizontal Placement C.G & \multirow{17}{*}{ Chest } \\
\hline 0.42 & 1.37 & 1.43 & 1.23 & 1.16 & 0.86 & 0.83 & 0.80 & Vertical Placement C.G & \\
\hline 1.81 & 1.58 & 1.60 & 1.23 & 1.16 & 1.00 & 1.04 & 1.73 & Resultant placement C.G & \\
\hline $1.70^{-}$ & $1.09-$ & $1.12^{-}$ & $0.20^{-}$ & 0.15 & 1.06 & 1.24 & 1.36 & Horizontal Placement R.H & \\
\hline 0.96 & 0.97 & 0.95 & 2.13 & 2.08 & 1.21 & 0.87 & 0.02 & Vertical Placement R.H & \\
\hline $1.89-$ & $1.16^{-}$ & $1.08^{-}$ & $0.32-$ & 0.01 & 0.77 & 0.97 & 1.91 & Horizontal Placement L.H & \\
\hline 0.91 & 0.91 & 0.85 & 2.16 & 2.14 & 1.65 & 1.58 & 0.09 & Vertical Placement L.H & \\
\hline $2.24-$ & $0.26^{-}$ & $0.24-$ & 0.37 & 0.46 & 0.73 & 0.73 & 0.78 & Horizontal Placement R.F & \\
\hline 0.84 & 1.07 & 0.91 & 0.27 & 0.16 & 0.07 & 0.08 & 1.20 & Vertical Placement R.F & \\
\hline $2.37-$ & $0.27-$ & $0.22-$ & 0.01 & $0.02-$ & $0.01-$ & 0.01 & 1.85 & Horizontal Placement L.F & \\
\hline 0.73 & 1.00 & 0.88 & 0.03 & 0.00 & 0.01 & 0.03 & 1.73 & Vertical Placement L.F & \\
\hline 3.10 & 2.62 & 2.06 & 4.94 & 3.15 & 3.87 & 2.85 & 3.10 & Horizontal Velocity C.G & \\
\hline 0.44 & 1.05 & 1.68 & 3.15 & 2.98 & 1.17 & 0.75 & 0.44 & Vertical Velocity C.G & \\
\hline 3.13 & 2.82 & 2.66 & 5.86 & 4.73 & 4.04 & 2.95 & 3.13 & Resultant Velocity C.G & \\
\hline $13.5^{-}$ & $60.17-$ & 63.94- & $89.12^{-}$ & $82.85^{-}$ & 59.46 & 53.20 & 27.71 & Angular change C.G & \\
\hline 81.54 & 166.80 & 150.89 & 158.11 & 178.21 & 93.89 & 93.81 & 143.86 & Angular change SH & \\
\hline 76.23 & 82.33 & 93.62 & 175.68 & 169.29 & 119.49 & 103.07 & 124.36 & Angular change TH & \\
\hline $0.93^{-}$ & $0.43^{-}$ & $0.38^{-}$ & $0.08^{-}$ & $0.14^{-}$ & 0.05 & 0.11 & 0.57 & Horizontal Placement C.G & \multirow{9}{*}{ Back } \\
\hline 0.47 & 1.31 & 1.33 & 1.15 & 1.26 & 0.95 & 0.97 & 1.10 & Vertical Placement C.G & \\
\hline 1.04 & 1.37 & 1.38 & 1.15 & 1.27 & 0.95 & 0.97 & 1.24 & Resultant placement C.G & \\
\hline 1.39 & 0.67 & 1.17 & 0.93 & 1.50 & 0.96 & 1.45 & 1.39 & Horizontal Velocity C.G & \\
\hline 0.14 & 0.77 & 0.42 & 2.28 & 2.85 & 0.62 & 0.48 & 0.14 & Vertical Velocity C.G & \\
\hline 1.39 & 1.02 & 1.25 & 2.46 & 3.22 & 1.14 & 1.53 & 1.39 & Resultant Velocity C.G & \\
\hline $26.5^{-}$ & $72.82-$ & $74.08^{-}$ & $83.81-$ & $82.67-$ & 87.08 & 83.71 & 62.58 & Angular change C.G & \\
\hline 78.81 & 87.36 & 77.56 & 145.61 & 101.88 & 75.08 & 79.65 & 83.48 & Angular change SH & \\
\hline 25.84 & 141.94 & 146.31 & 72.07 & 78.34 & 177.78 & 167.00 & 172.49 & Angular change TH & \\
\hline
\end{tabular}

Figure (1)

The temporal distribution of stages of high jump performance skill in tow technique ( chest - back) .

\section{Traditional}

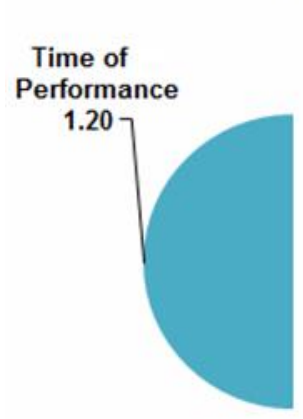

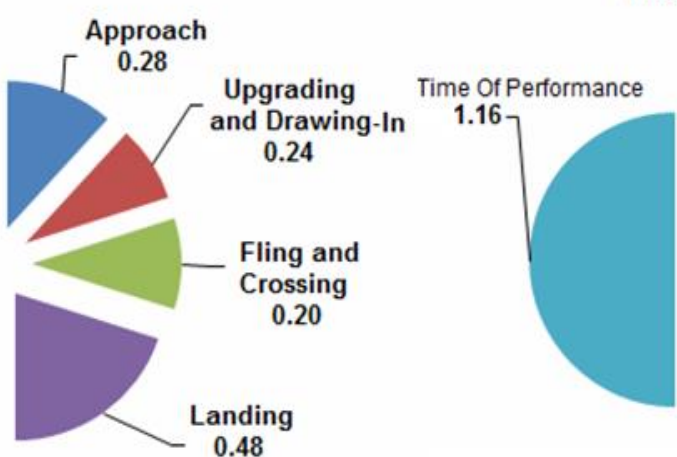

Innovative

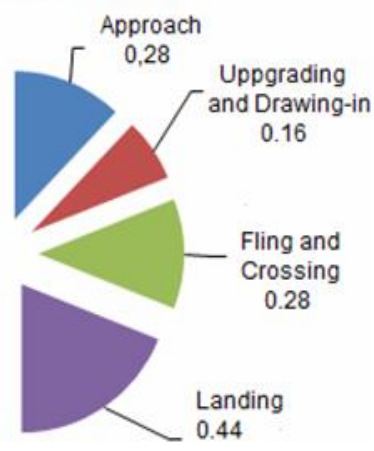


Figure (2)

Geometric path of gravity center of body for the two technique ( chest " above curve "، Back ) in the high jump competition.

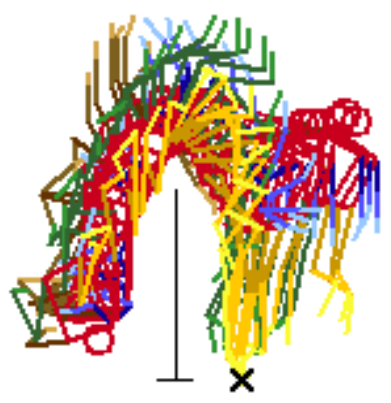

Back Technique (traditional)

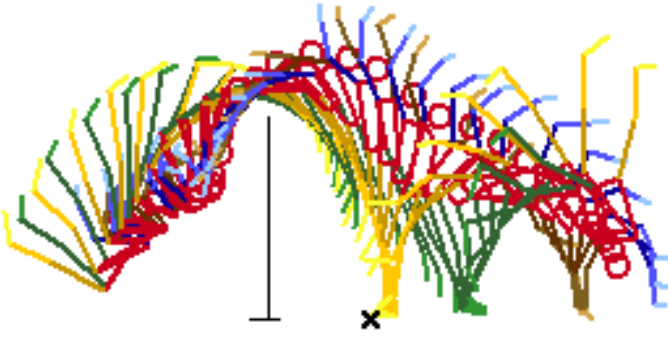

Chest Technique (innovative)

Figure (3)

curve speed of center gravity of the body for the two technique the Chest

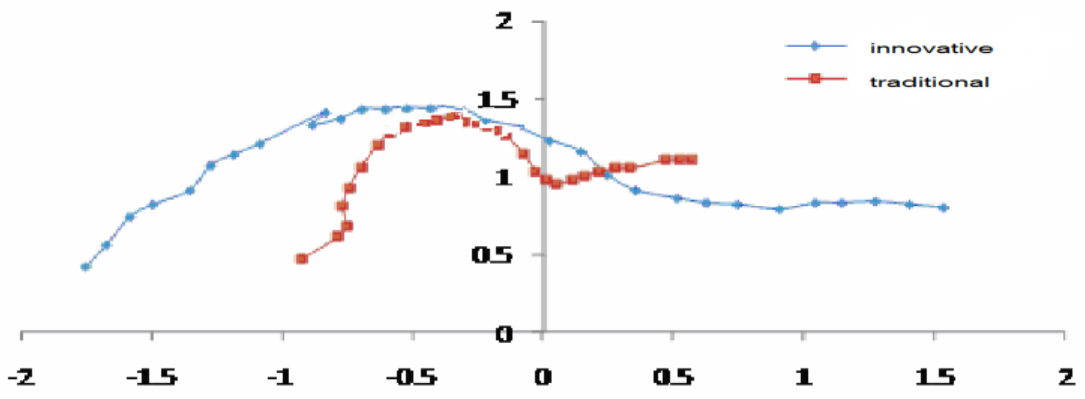

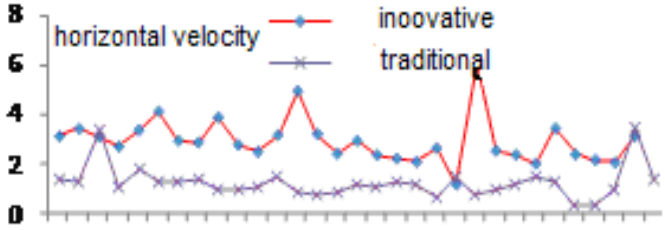

1355791113151719212325272931

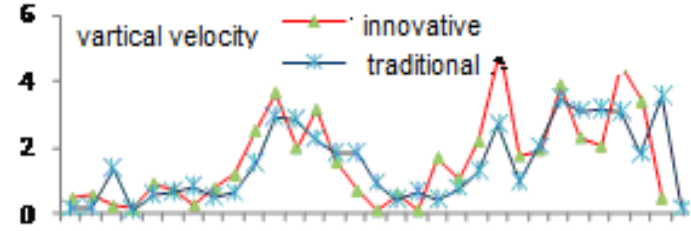

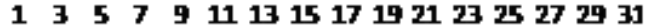

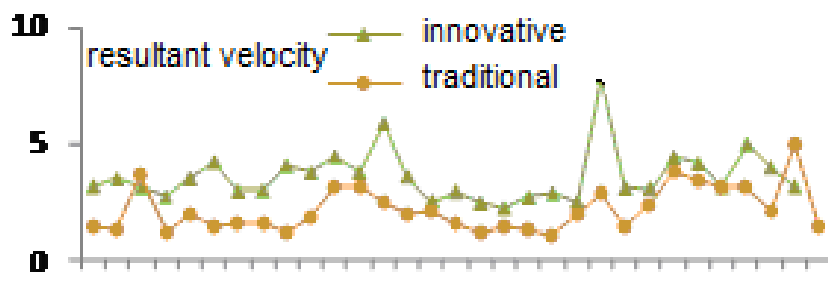

$\begin{array}{llllllllllllll}1 & 3 & 5 & 7 & 9 & 11 & 13 & 17 & 21 & 23 & 27 & 29 & 31\end{array}$ 
figure (4)

curve for angular change of center of gravity of the body around upgrade point for the two technique the Chest (innovative) and the Back technique (traditional) in high jump competition

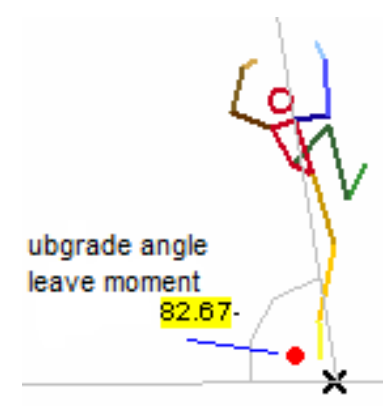

BackTechnique (traditional)

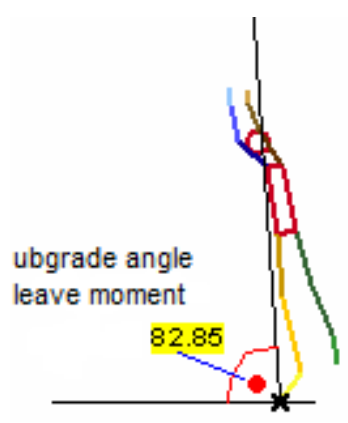

Chest Technique

(innovative)

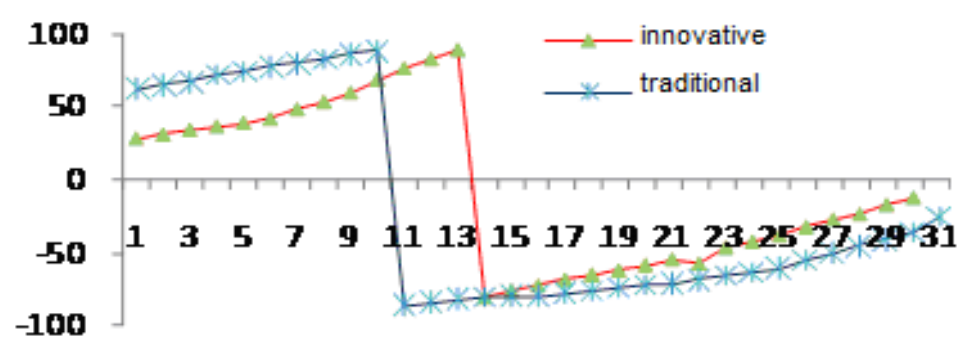

Table (2) show that the innovative technique was equal to the traditional one in the time of approaching stage and was less in the time of upgrading stage; which means that it the faster . It increased in the time of flying; which means that it is the higher. But it decreased in the time of landing as a result of kinesthetic of the torso and legs. It also decreased in the total time of the skill as a result of the fasting of the total performance of the skill, which output of the fasting of its stages specially the approach and upgrading stages. "Mohammed Barkaa", kayriaa alsokary " 2004 refers that time is the only independent variable in mechanics and it is one of the important dimensions in all mathematics (15-75) . Table (3) and figures (2-4) show that the innovative technique is more than the traditional one through all the stages of performance in the variables of horizontal and resultant displacement and in the end of flying stage for vertical distance. While it decreased in the approach and upgrading stages, starting point of flying and the ending point of landing. As a result of decreasing of gravity center of body in the direction of the ground when the torso moves up and down during "side round with quarter roll" in order to do quick somersault for the torso helping in upgrading quickly which increases the height of gravity center of body in the end of rotation (draw-in). In this way refer " Dapena,J" 2000, "Alexender.r" 1995 ,that the average of rushing in vertical movement depends from side on the strength of muscles and swing during push and the power of earth gravity from other side, in spite of ,that the power of earth gravity agree directly with body weight and conversely with strength of muscles $(8: 246)(4: 327)$.

the innovative technique is more than the traditional one in the values of all horizontal, vertical and resultant speed in all performance stages of body`s gravity center as a result of approach body somersault as a result of rotating the body around itself either in the quarter roll of the side wheel or the front aerobic circle over the crossbar. the innovative technique is less than the traditional one in the values of angular change of body`s gravity center in all performance stages except the end of the upgrading and the start of flying as it is more than the traditional. This means that the vertical vehicle of movement increases which agree with mechanical goal of high jump skill. It is an attempt to achieve the body as a shoot to the maximum vertical distance.This is what "Adel Abdel Baseer"," Ali,Ehab Adel Abdel " 2007 ( 2:470) has assured .

the innovative technique is more than the traditional one in the values of shoulder's joint, which means that the arms were stretching over the head ; while it is less than the traditional technique in values of thigh`s joint in most performance stages.Because it depends on contracting the thigh unlike the traditional one.there are two relationships ,one is forward between body's parties (center of gravity, hands,foot) as the horizontal displacement decrease and the vertical increase.This means that there is good agreement between them which agree with an important principle of Mechanics "compatibility the pushing towards the target" . 
This is what both of " Jarde Hwoghmoth"1999 , "Yousef Alshakh" 1982 (10:329) , (17:318) has referred to. The other relation is the backward one between the horizontal and the vertical distances of body's parties through the stages of performance. This means that body`s parties turn well from the horizontal to the vertical vehicle, which is the main purpose of high jump performance.

\section{Conclusions:}

- The proposed educational programs have an positive effect on the kinetic learning and the mechanical variables(under consideration) to perform the high jump skill by two ways(innovative and traditional).(attachment 14).

- The innovative technique and traditional one have a great effect and technical description and biomechanical values in the and of core mechanical performance of high jump in athletic. Table (2-3), Attachment $(1,3)$.

- The innovative technique is more the traditional one in the values of : The time of upgrading as it was(.16: .24 Sec),flying(..20 Sec) . -The variables of displacement of body's gravity center in most stages of performance specially the end of flying. The horizontal displacement was(.70:.38 M),the vertical was $(1.43: 1.33 \mathrm{M})$ and the resultant was( 1.60: 2.46M).respectively. - The variables of speed of body`s gravity center in most stages of performance specially in the start of flying. The horizontal displacement was(70:38 M),the vertical was $(1043: 1033 \mathrm{M})$ and the resultant was $(5.86: 2.46 \mathrm{~m} / \mathrm{Sec})$ respectively. - The angular change of body`s gravity center in the end of upgrading was(82.85:82.67 angel) and in the starting of flying was(89.12: 83.81angel) respectively. - The angular change of shoulder`s joint in the end of upgrading of innovative technique was(178.21angel) and in the starting of flying of traditional technique was(177.78angel) respectively.

- The innovative technique was less than the traditional one in the values of : Time of landing $(.44: .48 \mathrm{Sec})$ and the total time (1.16:1.20Sec) respectively. - The angular change of thigh's joint which reached to the minimum point in the end of landing $(76,23: 25.84)$ respectively.

- The innovative technique was equal with the traditional one in the values of approach which was $(.28 \mathrm{Sec})$ for each one. - There are forward relation between body`s parties (body`s gravity center-armsfoot) in all variables of displacement ,speed and angular change. While there are backward relation between the horizontal and vertical vehicle during the stages of performance.
- It might be predicted with the distance of high jump of the good player by the innovative technique through the following equation :

The distance of good high jump =

the length of jump + the distance of vertical jump

from stretching stability.(attachment "6")

\section{Recommendation:}

- Leaning the innovative technique for the younger in order to achieve international numbers.

- Applying the two proposed programs to learn how to perform high jump skill by the innovative or the traditional technique.

- Applying the values of the previous conclusions for the mechanical variables of the body technical performance during learning high jump by the innovative or the traditional technique in terms of the total performance and its stages, variables of displacement and speed(horizontal, vertical and resultant) and the angular change of body's gravity center-arms-foot through the performance.

- Performing by the innovative technique quickly according to the speed of pelvis rotation up then the speed of knee rotation in the same direction of the pelvis. Rotating the pelvis quickly in the traditional technique before the body's gravity center reaches at the level of crossbar .knees rotation has been done after the center of gravity cross the bar.

- In order to do the wheel with quarter roll, conjoin the foot gradually during going up until they become closed nearly in the higher vertical point on the body`s gravity center then open them gradually during the landing until they reach to the distance equaled to the width of pelvis or double distance.

- The length of the performer represents the body abilities (speed, flexibility, ability of muscle, agility and agreement). The technique of rotation has an important in achieving the best performance of high jump by the two technique (innovative and traditional), but the innovative one depends on the quantitative and qualitative technique of rotation more than the traditional technique.

- Take the predictive equation of high jump distance for the good players when you select and prepare the talent players in this competition. 


\section{References:}

1- Adashevskiy V .M . Lermakov S .S ,Marchenko A . A : Biomechanics aspects of high jump, physical education of students ,2013, volume 2

2- Adel Abdel-Baseer Ali,Ehab Adel Abdel-Baseer:' biomechanic analysis and the integration between the theory and application in the sportive field, Egyptian Library for print and publishing ,Alexandria, 2007.

3- Ahmed Abdel Aziz Salama, Ahmed Abdel Salam Abdel Ghaffar: Cattell testing for intelligence, the Arab Renaissance House, Cairo, 1970

4- Alexander ,R : Optimum take off technique for high and long jump .philosophical Transactions of the Royal Society . B 327, 3-10 .1990 .

5- Alyaa Hussein Daham,Hedar Falyh Hassan : " the effect of physical exercises and some helped performances in mechanic kinetic and achievement for performing high jump effectively ,Science of Physical education journal, second edition ,volum4 ,Faculty of physical education,Babel University,2011.

6- Atef Samh Mohammed Mahros : " The effect of multi-levels self-education program on the skill of high jump for the younger players of athletic ,unpublished Master, Faculty of physical education,Minia University,1997.

7- Bastawesi Ahmed Bastawesi: “ competitions of track and field(learning-technique-training),Dar Alfker Alaraby,Cairo, 1997.

8- Dapena ,J .The high jump : in V . Zatsiorsky (Ed .), Biomechanics in sport (pp . 280 -312) Blackwell science : Oxford , 2000

9- Greig ,M .P . and Yeaden ,M .R : The influence of touchdown Parameters on the performance of high jumper .J.A PP . Biomechanics $16 ; 362-378$. 2000

10- Jaird Hokhmouth : translated by Kamal AbdelHamed,Soliman Ali Hassan( the biomechanics and the techniques of scientific search of sport movements, Center of book for publishing,Cairo,1999.

11- Jesus dapena ; biomechanical studies in the high jump and the implications to coaching Track \&
Field Quarterly Review, George D. Gales, editor Vol 92, No. 4, winter 1992. Re-printed with permission from Modern Athlete and Coach

12- Jozeh Manul Balstyrwes: the principles of learning and sport training in athletic,translated by Osman Refat,Mahmoud Fathy, The international union of athletic,National center of development,Cairo,,1992 .

13- Khaled Yahia Fekri : (the effect of a training program to improve the kinetic speed on the digital level for the younger players of high jump by back technique, Master, Faculty of physical education ,Tanta University,2008.

14- Moataz Mohammed Nageeb Alsaied: "Biomechanic example for high jump players,Master, Faculty of physical education ,TantaUniversity,2010

15- Mohammed Gaber Barkea,Khayria Alsokary: the main principles for biomechanics in the sportive field,Maaref,Alexandria,2004.

16- Mohammed Soubhey Hasanein : Measurment and evaluation in physical education ,the first part ,edition 4,Dar Alfker Alaraby,Cairo,1999.

17- Mohammed Yousef Alshakh: "Biomechanic and its application", Dar Alfker Alaraby ,Cairo, 1982.

18- Moustafa Moustafa Ali Mohammed Atwa,Ashraf Ahmed Mokhtar Helal,Salm Hassan Salm: " Biomechanics of upgrading in the high jump using Falob Technique ,Faculty of physical education for males ,Helwan University,2001.

19- Moustafa Moustafa Ali Mohammed Atwa: “ An analytical study for the pendinf of the approach in the high jump using Falob Technique ,Master,Faculty of physical education ,Helwan University,1997.

20- Osama Mohmmed Abdel-Aziz Ahmed: “ The effect of an educational program using hypermedia on learning the skill of high jump for younger players" Master,Faculty of physical education.Minia University 2001.

21- Talha Hussein Housam AL-din: biomechanics "Theoretical and practical bases" ,Dar Alfker Alaraby,Cairo ,1993 
